\title{
The Effects of Low Energy Irradiation on Organometallics. Organometal Halides of Group IVA'
}

\author{
F. E. Brinckman, Gerald F. Kokoszka, ${ }^{2}$ and Norman K. Adams, Jr. \\ Institute for Materials Research, National Bureau of Standards, Washington, D.C. 20234
}

(November 27, 1968)

\begin{abstract}
A group of selected group IVA halides of the type $\left(\mathrm{CH}_{3}\right)_{n} \mathrm{MCl}_{4-n}$, where $n=0,1,3$ and $\mathrm{M}=\mathrm{Si}$, Ge, Sn have been subjected to low-energy irradiation $(254$ and $370 \mathrm{~nm})$ in the condensed phase at $-196^{\circ} \mathrm{C}$. This survey also examined related compounds including $\mathrm{HSiCl}_{3}, \mathrm{CH}_{2} \mathrm{ClSiCl}_{3}, \mathrm{CH}_{3} \mathrm{SiF}_{3}, \mathrm{CH}_{3} \mathrm{SiHCl}_{2}$ as well as cocondensed mixtures. It is demonstrated by EPR spectroscopy that these conditions suffice to cleave $\mathrm{M}-\mathrm{C}$ bonds. By following spectral changes during or following irradiation, as a function of time, it is demonstrated that both primary and secondary reactions occur. Some general features of the spectra are discussed and certain conclusions are projected to additional studies on low temperature reactions in 1:1 cocondensed mixtures of organometal halides. Some preliminary supporting evidence from mass spectrometric observations is discussed.
\end{abstract}

Key words: EPR; free radicals; germanium; irradiation; low-temperature reaction; organometallic compounds; silicon; tin.

\section{Introduction}

Numerous examples of organic free radicals arising from organometallic compounds have been shown by various spectroscopic techniques $[1]^{3}$; however, relatively few data are presently available concerning those radicals produced from organometal halides [2a]. This class of compounds is particularly interesting to us since under suitable conditions of excitation its members might serve as precursors to reactive organic, inorganic, or organometallic radical species whose existence is suggested from bulk product characterization in a variety of decomposition reactions.

In addition, considerable data are available on organic free radicals in the solid state. The review by Morton [3] discusses some of the studies on single cyrstals and the recent book by Atkins and Symons [4] also covers references in this area. The general electron paramagnetic resonance properties of this class of radicals have been known for some time. More recently a number of studies have been reported which characterize essentially inorganic free radicals $[3,6]$. Often these studies are carried out on rather small quantities of the parent material imbedded in a rare gas matrix. Such conditions are generally believed to be important since they produce a reasonably isotropic local environment which fosters rapid

Portions of this work were presented at the Symposium on Organometallic Radicals, Am. Chem. Soc., 153rd Nat'l. Mtg., Miami Beach, Fla., April 1967.

2 Present address: Dept. of Chemistry, State Univ. of N.Y., Plattsburgh, N.Y. 12901

Figures in brackets indicate the literature references at the end of this paper. rotation of the molecular fragments. This situation is desirable since a rapidly rotating radical generally is characterized by relatively narrow electron paramagnetic resonance lines which often aid in the identification of the radical.

High-energy irradiation sources seem to predominate in the study of radicals; often $\gamma$-irradiation is a convenient source while $x$-ray irradiation has also been widely used. The utilization of relatively low-energy sources does not seem to have been widely exploited. It appeared that consideration should be given to this technique since low-energy irradiation might be expected to disrupt the parent material much less than higher energy sources with fewer bonds cleaved and/or fragments ionized. This should result in fewer, relatively simpler species which might be more easily characterized. Further, when more complicated spectra arise it may be possible to identify the nature of the reaction. In this connection, the interesting work of Roncin [2b] deserves comment. Some of the systems which we have investigated using low energy irradiation have been simultaneously investigated by Roncin with $\gamma$ irradiation. This higher energy source has produced some additional radicals which we do not observe, but this work bears a complementary relation to the work discussed in the present paper.

As a part of a more general study dealing with free radicals incorporating elements other than carbon [5], we have recently turned to an investigation of the consequences of low energy irradiation of polycrystal- 
line organometallic halide substrates. These studies have been carried out chiefly at liquid nitrogen temperature. Our principal interest was to gain information about the nature of bond cleavage in these compounds when they are subjected to low energy irradiation. In organometal halides such as we are considering here low symmetries in the condensed phase, and the expected comparative immobility of large halometalloid radicals, such as that recently described [7] for $\cdot \mathrm{SiCl}_{3}$ below $-150{ }^{\circ} \mathrm{C}$, encouraged our starting point at liquid nitrogen temperature. In this way, concurrent small, possibly mobile, but hopefully rotating species could be identified, and ultimately the more complex spectral elements associated with large fragments could be characterized under a variety of conditions.

Once the comparative modes of fragmentation in these compounds have been ascertained, this knowledge could be used to obtain a wide variety of new radicals by properly selecting the appropriate isolation matrix and/or the correct temperature. Our studies along these lines will be the subject of a future paper. For the present survey purposes we have chosen the stated conditions so as to minimize complicating spectral features since the parent compounds are, by choice, rather complex molecules.

\section{Experimental Procedures}

\subsection{Organometal Halides}

All compounds studied were obtained from commercial suppliers or synthesized by literature methods in this laboratory. Purification and other manipulations were accomplished in an efficient recirculating drybox and a conventional high-vacuum system. Purity is estimated (by infrared spectra, vapor pressure, NMR spectra) at about 99 percent with obvious contaminants (i.e., $\mathrm{HCl}$, oxygen) absent prior to sealing off in vacuo at $-196{ }^{\circ} \mathrm{C}$ in $4 \mathrm{~mm}$ O.D. fused silica tubes. The 1:1 cocondensed samples were frozen into sample tubes at a slow rate from low pressure gas mixtures.

\subsection{Electron Paramagnetic Resonance}

The EPR data were obtained at liquid nitrogen temperature with an X-band spectrometer. The cavity was equipped with irradiation slots allowing a continual monitoring of the EPR signal as a function of time for continuous irradiation. In general the rate of build up of spectral intensity followed first-order kinetics, namely $I=I_{0}\left(1-e^{-t / \tau}\right)$. In this expression, $I_{0}$ represents the intensity expected with $t \rightarrow \infty$ and $\tau$ is a characteristic time which is a function of the experimental configuration. In these experiments, $\tau$ was in the range of $20 \mathrm{~min}$ to $100 \mathrm{~min}$, thus allowing adequate data to be gathered in a single day. A typical build up curve is shown in figure 1. The sample is $\mathrm{CH}_{3} \mathrm{SiHCl}_{2}$ irradiated by the commercial high-pressure $200 \mathrm{~W}$ mercury lamp $(300-600 \mathrm{~nm}$ with $\lambda$ max $\approx 370 \mathrm{~nm})$ used in all of these experiments. Since no change in line width of the spectra was observed over the period indi-

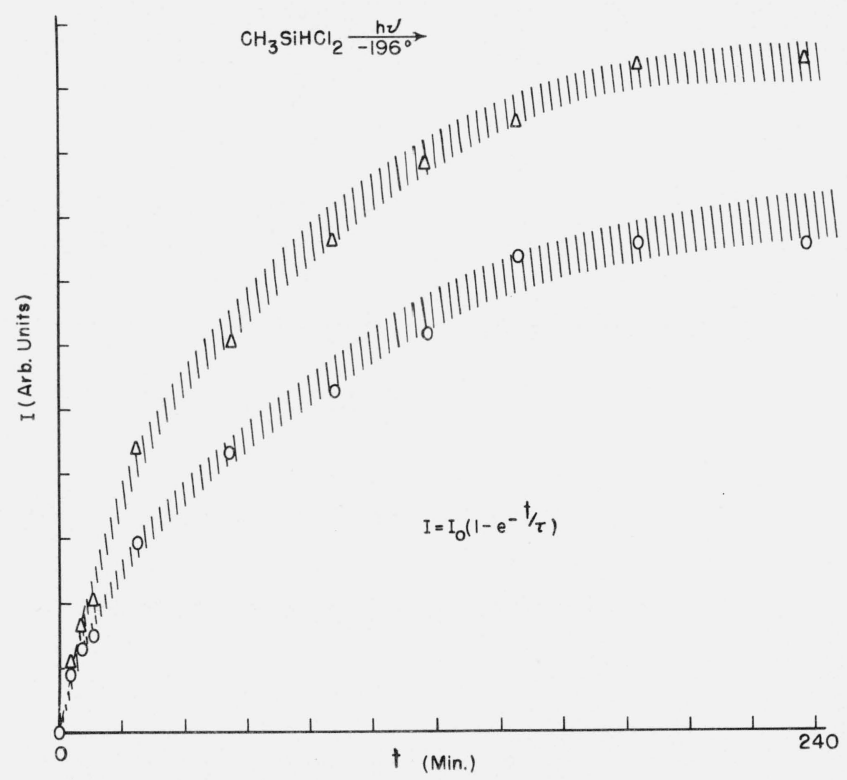

FigURE 1. Build up curve for $\mathrm{CH}_{3} \mathrm{SiHCl}_{2}$.

Upper curve developed from central component, lower curve developed from sum of two outer peak intensities. Vertical hatch marks represent maximum estimated uncer tainty, in intensity.

cated in the figure, it is sufficient to plot the peak height. The width of the lines represents the maximum estimated uncertainty in intensity.

Samples which were studied over longer periods were initially irradiated by the high pressure mercury lamp for a period of about $4 \mathrm{hr}$. The EPR spectrum was then immediately obtained. The samples were stored at liquid nitrogen temperature and examined every 24 to $48 \mathrm{hr}$ in most cases. The day-to-day reproducibility of a comparison sample of DPPH was better than 8 percent with relatively little special care and it is assumed that this sort of peak height reproducibility is also characteristic of the organometallic samples.

\subsection{Macro-Irradiation of Methyldichlorosilane}

One additional experiment with $\mathrm{CH}_{3} \mathrm{SiHCl}_{2}$ utilized a small ultraviolet source $(2.5 \mathrm{~W}$ with $92 \%$ at $253.7 \mathrm{~nm})$ in conjunction with an analytical mass spectrometer ( $180^{\circ}$ single-focusing, magnetic scan, resolution $=\frac{\mathrm{M}}{\Delta M}$ $\geqslant 250$ [8]) for determining non-condensible products formed during photolysis at $-196{ }^{\circ} \mathrm{C}$. The apparatus used provided insertion coaxially of the ultraviolet probe lamp into a borosilicate glass sample tube, achieving a vacuum-tight seal with polyfluorocarbon O-ring joints. This arrangement permitted a purified sample of $\mathrm{CH}_{3} \mathrm{SiHCl}_{2}$ (ca. $1 \mathrm{mmol}$ ) to be condensed directly from the high-v cuum line as a thin film on the walls of the sample tube. Following this, the apparatus was valved off (polyfluorocarbon valve stopcocks only) and then attached to the mass spectrometer in a direct inlet mode while the sample was maintained at -196 ${ }^{\circ} \mathrm{C}$. Examination of background gases $\left(2-3 \times 10^{-8}\right.$ torr $)$ in this irradiation setup indicated only traces of 
$\mathrm{N}_{2}(m / e=28)$ greater $(\sim 15$ scale divisions $)$ than baseline noise ( $2-3$ scale divisions).

Within several minutes of turning on the ultraviolet lamp, appreciable amounts of $\mathrm{H}_{2}(m / e=2)$ formed, reaching a maximum value $(\sim 330$ scale divisions, $\sim 1 \times 10^{-7}$ torr) in 40-50 min followed by diminution of $\mathrm{H}_{2}$ as starting material reacted. An evaluation of comparable formation of noncondensible $\mathrm{CH}_{4}$ $(m / e=15-16)$ maxima revealed in several runs the same pattern of rapid, dominant $\mathrm{H}_{2}$ production over that of $\mathrm{CH}_{4}$.

\section{Results}

\subsection{Methylchlorometallic Compounds}

The compounds chiefly studied were of the group $\left(\mathrm{CH}_{3}\right)_{n} \mathrm{MCl}_{4-n}$ for $n=1$ and 3 and $\mathrm{M}=\mathrm{Si}, \mathrm{Ge}$, and $\mathrm{Sn}$. A number of additional compounds such as $\mathrm{CH}_{3} \mathrm{SiF}_{3}$, $\mathrm{CHCl}_{2} \mathrm{SiCl}_{3},\left(\mathrm{CH}_{2} \mathrm{Cl}\right) \mathrm{SiCl}_{3}, \mathrm{CH}_{3} \mathrm{SiHCl}_{2}$ and a number of mixtures (vide infra) were also irradiated under comparable conditions in order to assess limits of the low-energy method. With one notable exception (see para. 3.2), in all compounds containing a $\mathrm{CH}_{3}$ moiety, evidence for the formation of methyl radical was unambiguous [9]. The four-line pattern with relative intensities in the ratio of about 1:3:3:1, the separation between the four components of about $23 \times 10^{-4} T$ and the $g$-value close to the spin-only value are the characteristics of this well-known radical species. The peak-to-peak linewidth varied slightly from precursor to precursor but the range from 1 to $4 \times 10^{-4} T$ easily included them all. Data were usually obtained using a modulation amplitude somewhat larger than these values in order to maximize the signal-to-noise ratio. The magnetic parameters for the methyl radicals produced from the various sources are listed in table 1. No dramatic change in the $g$ or $A$ values is noted as the host lattice is changed. It seems likely that the small rapidly rotating methyl radical is trapped on surfaces or in vacancies in the lattice or any other place where a sufficiently large hole is available.

TABLE 1. Summary of magnetic parameters for $\mathrm{CH}_{3} \mathrm{MCl}_{3}$ and $\left(\mathrm{CH}_{3}\right)_{3} \mathrm{MCl}^{\text {a }}$

\begin{tabular}{|c|c|c|c|}
\hline & $g$ & $H_{\mathrm{pp}}^{\mathrm{b}}$ & $A^{\mathrm{b}}$ \\
\hline $\mathrm{CH}_{3} \mathrm{SiCl}_{3} \ldots \ldots$ & 2.0025 & 3.2 & 22.8 \\
\hline $\mathrm{CH}_{3} \mathrm{GeCl}_{3} \ldots \ldots \ldots \ldots$ & 2.0036 & 2.9 & 23.3 \\
\hline $\mathrm{CH}_{3} \mathrm{SnCl}_{3} \ldots \ldots \ldots \ldots \ldots$ & 2.0033 & 4.7 & 22.6 \\
\hline $\mathrm{CH}_{3} \mathrm{SiF}_{3} \ldots \ldots$ & 2.0030 & 4.6 & 23.1 \\
\hline$\left(\mathrm{CH}_{3}\right)_{3} \mathrm{SiCl} \ldots \ldots \ldots \ldots \ldots \ldots$ & 2.0032 & 4.3 & 22.7 \\
\hline$\left(\mathrm{CH}_{3}\right)_{3} \mathrm{GeCl} \ldots \ldots \ldots \ldots \ldots \ldots$ & 2.0031 & 4.4 & 23.0 \\
\hline$\left(\mathrm{CH}_{3}\right)_{3} \mathrm{SnCl} \ldots \ldots \ldots \ldots \ldots \ldots$ & 2.0032 & 3.4 & 22.7 \\
\hline
\end{tabular}

a The uncertainties in the $g$ values are estimated to be less than 0.0003 and for the $A$ values and for $H_{\mathrm{pp}}$, the peak-to-peak line width, less than $0.3 \times 10^{-4} T$

${ }^{\mathrm{t}}$ The units for $H_{\mathrm{pp}}$ and $A$ are $10^{-4} T$.

\subsection{Special Case of Methyldichlorosilane}

A compound excepted from the general trend of $\mathrm{CH}_{3}$ production is $\mathrm{CH}_{3} \mathrm{SiHCl}_{2}$ where simple $\mathrm{Si}-\mathrm{C}$ fission cannot explain the triplet spectrum observed with components separated by $\sim 20 \times 10^{-4} T$. That the observed result stems from rapid secondary or com petitive processes involving both $\mathrm{Si}-\mathrm{C}$ and $\mathrm{Si}-\mathrm{H}$ bonds was considered in the macro-irradiation experiment, and the interesting apparent ${ }^{4}$ dominance of $\mathrm{H}_{2}$ production over $\mathrm{CH}_{4}$ definitely requires consideration of an additional consecutive mechanism involving possibly both $\mathrm{H}-\mathrm{C}$ and $\mathrm{Si}-\mathrm{H}$ bonds [10]. Thus, if we assume initial $\mathrm{Si}-\mathrm{C}$ cleavage analogous to that of $\mathrm{CH}_{3} \mathrm{SiCl}_{3}$

$$
\mathrm{CH}_{3} \mathrm{SiHCl}_{2} \stackrel{h \nu}{\longrightarrow} \mathrm{CH}_{3} \cdot+\cdot \mathrm{SiHCl}_{2}
$$

and the $\mathrm{CH}_{3} \cdot$ is sufficiently mobile to immediately abstract a proton from a nearby parent molecule [2], several reaction courses are possible:

$$
\begin{aligned}
& \mathrm{CH}_{3} \cdot+\mathrm{CH}_{3} \mathrm{SiHCl}_{2} \stackrel{(1)}{\longrightarrow} \mathrm{CH}_{4}+\mathrm{CH}_{3} \dot{\mathrm{SiCl}}_{2} \\
& \stackrel{(2)}{\longrightarrow} \mathrm{CH}_{4}+\cdot \mathrm{CH}_{2} \mathrm{SiHCl}_{2} \text {, as well as } \\
& \stackrel{(3)}{\longrightarrow} \mathrm{C}_{2} \mathrm{H}_{6}+\cdot \mathrm{SiHCl}_{2} .
\end{aligned}
$$

Although reaction (3) would appear unlikely, some mass spectrometric evidence was obtained suggesting presence of small amounts of $\mathrm{C}_{2} \mathrm{H}_{6}(\mathrm{~m} / \mathrm{e}=29-30)$ on slight warming of sample $\left(5 \times 10^{-7}\right.$ torr $)$. Reaction (2) seems least likely in view of rather slow diminution of $\mathrm{CH}_{3} \cdot$ from analogous $\mathrm{CH}_{3} \mathrm{SiCl}_{3}$.

However, since $\mathrm{H}_{2}$ is rapidly formed during photolysis an alternate explanation is necessary for its production which also explains the absence of $\mathrm{CH}_{3} \cdot$ quartet:

$$
\text { initiation: } \mathrm{CH}_{3} \mathrm{SiHCl}_{2} \stackrel{h \nu}{\longrightarrow} \mathrm{CH}_{3} \dot{\mathrm{SiCl}}_{2}+\mathrm{H} \text {. }
$$

$$
\begin{aligned}
\text { propagation: } \mathrm{H} \cdot+\mathrm{CH}_{3} \mathrm{SiHCl}_{2} & \stackrel{(4)}{\longrightarrow} \cdot \mathrm{CH}_{2} \mathrm{SiHCl}_{2}+\mathrm{H}_{2} \\
& \stackrel{(5)}{\longrightarrow} \mathrm{CH}_{3} \mathrm{SiCl}_{2}+\mathrm{H}_{2} \\
& \stackrel{(6)}{\longrightarrow} \mathrm{HSiCl}_{2}+\mathrm{CH}_{4}
\end{aligned}
$$

Reactions (4) and (6) are preferred since these explain not only the observed $\mathrm{H}_{2}$ and $\mathrm{CH}_{4}$ production, but also (4) offers a reasonable radical species giving rise to a triplet spectrum (vide infra).

\section{3. $\alpha$-Chloromethylchlorosilanes}

The compound $\mathrm{CH}_{2} \mathrm{ClSiCl}_{3}$ produced a three-line pattern with relative intensities $1: 2: 1$. The separation

\footnotetext{
${ }^{4}$ While $\mathrm{CH}_{3} \cdot$ production rate could even exceed that of $\mathrm{H} \cdot$, relative mobilities of $\mathrm{H} \cdot$ or $\mathrm{H}_{2}$ and $\mathrm{CH}_{3} \cdot$ or $\mathrm{CH}_{4}$ in the host lattice followed by degassing under these experimental conditions are not known, hence only an "apparent" difference is suggested.
} 
between the components was about $18 \times 10^{-4} T$ and the outer two components were somewhat broader than the inner one. This pattern is assigned to the radical $\mathrm{CH}_{2} \mathrm{Cl} \cdot$ where chlorine structure is not resolved. This result is also consistent with the hypothesis that the primary cleavage is that of the carbon-silicon bond. A further test of this idea might be exemplified by irradiation of $\mathrm{CHCl}_{2} \mathrm{SiCl}_{3}$, where in the most obvious process the $\alpha$-proton radical $\mathrm{CHCl}_{2}$ should afford a two-line spectrum, consistent with our earlier observations. However, to date experimental results have not yielded results as conclusive as in the $\mathrm{CH}_{2} \mathrm{ClSiCl}_{3}$ case.

\subsection{General Trends}

For those neat organometal chlorides producing methyl radicals on irradiation, examination of the spectral features seen in addition to the $\cdot \mathrm{CH}_{3}$ quartet permits classification of each parent compound into one of three distinct modes of behavior. The first group is characterized by the irradiation products of $\left(\mathrm{CH}_{3}\right)_{3}$ $\mathrm{GeCl}$ and $\left(\mathrm{CH}_{3}\right)_{3} \mathrm{SiCl}$. In both of these cases, a sevenline pattern seems to be the dominant spectral feature in addition to the methyl signal. The patterns in both cases are nearly identical with $A \approx 17 \times 10^{-4} T$ and an example of $\left(\mathrm{CH}_{3}\right)_{3} \mathrm{SiCl}$ is shown in figure 2 . An additional residual component may also be present in the $\left(\mathrm{CH}_{3}\right)_{3} \mathrm{SiCl}$ spectrum since the central peak is enhanced over that of the Ge analog.

A typical representative of the second group is provided by irradiation of $\mathrm{CH}_{3} \mathrm{GeCl}_{3}$. The spectrum obtained from this compound on the first day consists essentially of the four-line $\mathrm{CH}_{3}$. pattern with no underlying components apparent, while that obtained on the ninth day after irradiation is shown in figure 3 . Over this period of time the intensity of the methyl radical signal was roughly constant while the additional spectral components built up according to the rate law previously mentioned with a characteristic

$$
\begin{aligned}
& \left(\mathrm{CH}_{3}\right)_{3} \mathrm{SiCl} \\
& \quad \frac{h v}{-196^{\circ}} \\
& \quad 1 \quad+23 \times 10^{-4} \mathrm{~T}
\end{aligned}
$$
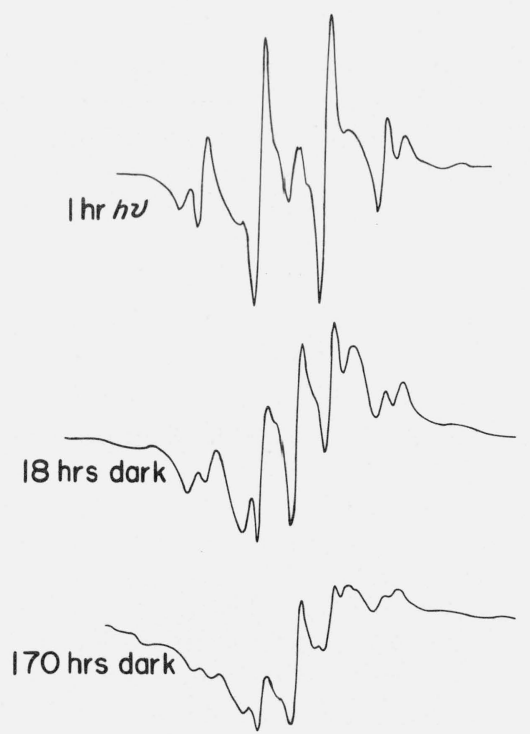

FIGURE 2. EPR spectra obtained from irradiated $\left(\mathrm{CH}_{3}\right)_{3} \mathrm{SiCl}$ as a function of time.

time $(\tau)$ of about three days. A similar time-intensity relationship was also observed after irradiation of $\mathrm{CH}_{3} \mathrm{SnCl}_{3}$ or $\left(\mathrm{CH}_{3}\right)_{3} \mathrm{SnCl}$.

A third mode of behavior is represented by only a single compound, $\mathrm{CH}_{3} \mathrm{SiCl}_{3}$. Following irradiation of this material as a function of time, the methyl signal decays over a period of days revealing an underlying triplet pattern not dissimilar to that of $\mathrm{CH}_{3} \mathrm{SiHCl}_{2}$. Figure 4 shows typical spectra obtained immediately after irradiation and $18 \mathrm{hr}$ after irradiation.

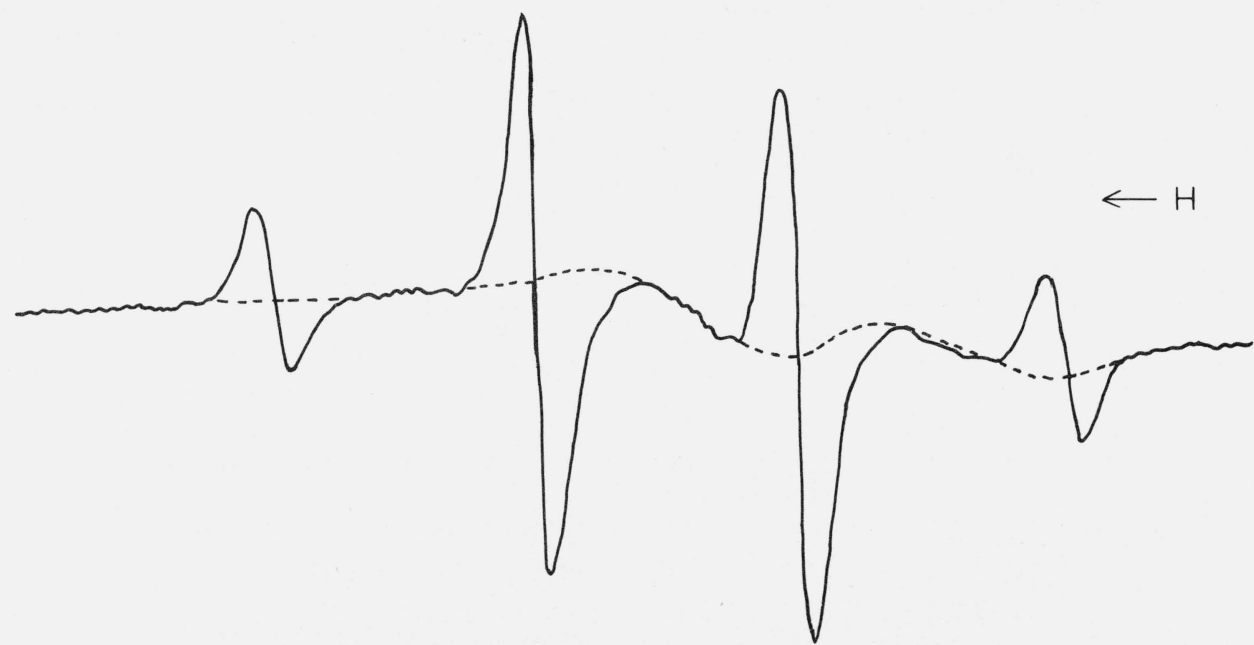

FIGURE 3. EPR spectrum of $\mathrm{CH}_{3} \mathrm{GeCl}_{3}$ obtained on ninth day after irradiation. 


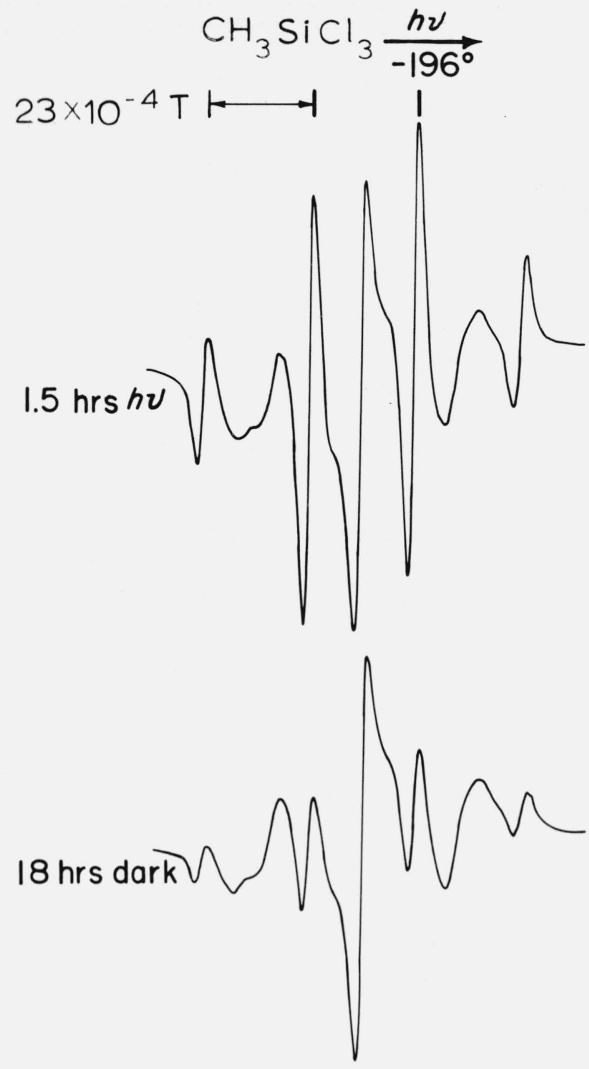

FIGURE 4. EPR spectra obtained from irradiated $\mathrm{CH}_{3} \mathrm{SiCl}_{3}$ as a function of time.

\subsection{Irradiation of Mixtures}

Since our experience with photolysis of $\mathrm{CH}_{3} \mathrm{SiHCl}_{2}$ indicated both primary and secondary processes might involve either $\mathrm{Si}-\mathrm{C}$ or $\mathrm{Si}-\mathrm{H}$ scission, a number of experiments emphasizing intermolecular processes were conducted (table 2). If the idealized 1:1 cocondensates afforded sufficient homogeniety, a possibility of processes uncharacteristic of either addend might ensue, indicative of the new reaction course(s) available. Table 2 summarizes our results compared with additive or no interaction behavior.

\section{Discussion}

The evidence presented in the previous section strongly indicates that the primary process which occurs upon irradiation is the cleavage of the metalloidcarbon. In this connection, we might also note that no radicals were observed when the halides $\mathrm{MCl}_{4}$ $(\mathrm{M}=\mathrm{Si}, \mathrm{Ge}$, or $\mathrm{Sn})$ were irradiated under comparable conditions. The results with the compounds in the second group, as typified by $\mathrm{CH}_{3} \mathrm{GeCl}_{3}$, further suggest that secondary processes might be quite important in producing noticeable spectral changes over comparatively brief periods of time.

The results on the compounds in category one may be rationalized in terms of a rather simple scheme

$$
\left(\mathrm{CH}_{3}\right)_{3} \mathrm{MCl} \stackrel{h \nu}{\longrightarrow} \cdot \mathrm{CH}_{3}+\left(\mathrm{CH}_{3}\right)_{2} \mathrm{MCl} \quad \mathrm{M}=\mathrm{Si}, \mathrm{Ge} .
$$

The dimethylchloro-silyl or -germyl radical would be expected to produce a symmetric seven-line pattern if the unpaired electron primarily interacts equivalently with the protons in the two methyl groups [11]. The remaining four-line pattern is associated with the methyl radical. As a function of time, spectral features associated with the larger radical alter very slowly compared to the methyl radical spectral decay pattern. Indeed, in the germanium compound the methyl signal is very small even after the first day. This suggests the possiblity of secondary recombination reactions, perhaps between two methyls excluding the larger metalloid-containing radicals. The decay of the signal associated with methyl iadicals as a function of time is no doubt affected by a number of reactions.

In the second group, the evidence for secondary processes is more pronounced. The initial $\mathrm{M}-\mathrm{CH}_{3}$ cleavage results in the production of methyl radicals while the assumed $\mathrm{GeCl}_{3}$ radical is not likely to be freely rotating and thus no sharp line spectrum is expected. The absence of a spectrum due to this species is not surprising when the results of Leray and Roncin [7] are taken into account. The growth of a secondary spectrum as a function of time, while the methyl spectrum remains essentially constant in intensity, suggests a process involving the $\mathrm{GeCl}_{3}$ species. Two possible mechanisms can be illustrated:

TABLE 2. Reactions of mobile radicals in "mixed" systems

\begin{tabular}{|c|c|c|c|c|}
\hline \multicolumn{3}{|r|}{ Source } & Result expected if no interaction & Result observed \\
\hline (1) & \multicolumn{2}{|c|}{$\mathrm{CH}_{3} \mathrm{SiHCl}_{2} \ldots$} & $\mathrm{CH}_{3} \cdot$ or possibly $\mathrm{H} \cdot \ldots \ldots \ldots \ldots \ldots$ & No $\mathrm{CH}_{3} \cdot$, no $\mathrm{H} \cdot$, triplet component. \\
\hline (2) & $\begin{array}{c}\mathrm{CH}_{3} \mathrm{SiCl}_{3} \\
+ \\
\mathrm{HSiCl}_{3}\end{array}$ & $1: 1 \ldots \ldots$ & $\mathrm{CH}_{3} \cdot \mathrm{H} \cdot \mathrm{unlikely}$, triplet from $\cdot \mathrm{CH}_{2} \mathrm{Si} \subset \ldots$ & $\begin{array}{l}\text { No } \mathrm{CH}_{3} \cdot \text { no } \mathrm{H} \cdot{ }^{\mathrm{H}} \text {, anisotropic spectrum } \\
\quad \text { similar to } \mathrm{CH}_{3} \mathrm{GeCl} l_{3} \text { and } \mathrm{CH}_{3} \mathrm{SnCl}_{3} \text {. }\end{array}$ \\
\hline (3) & $\begin{array}{c}\mathrm{CH}_{3} \mathrm{GeCl}_{3} \\
+ \\
\mathrm{HSiCl}_{3}\end{array}$ & $1: 1 \ldots \ldots \ldots$ & $\begin{array}{l}\mathrm{CH}_{3} \cdot \mathrm{H} \cdot \text { unlikely, anisotropic spectrum } \\
\text { underlying. }\end{array}$ & $\begin{array}{l}\text { Very small } \mathrm{CH}_{3} \cdot \text { component, no } \mathrm{H} \cdot \text { aniso- } \\
\text { tropic } \mathrm{CH}_{3} \mathrm{GeCl}_{3} \text { spectrum. }\end{array}$ \\
\hline
\end{tabular}




$$
\begin{aligned}
& \mathrm{CH}_{3} \mathrm{GeCl}_{3} \frac{h \nu}{-196{ }^{\circ} \mathrm{C}} \mathrm{CH}_{3} \cdot+\cdot \mathrm{GeCl}_{3} \\
& \cdot \mathrm{GeCl}_{3}+\mathrm{CH}_{3} \mathrm{GeCl}_{3} \frac{(1)}{\stackrel{(2)}{\longrightarrow}} \mathrm{HGeCl}_{3}+\cdot \mathrm{CH}_{2} \mathrm{GeCl}_{3} \\
& \mathrm{GeCl}_{4}+\mathrm{CH}_{3} \mathrm{GeCl}_{2}
\end{aligned}
$$

The anisotropic nature of the spectrum and the lack of any clear cut proton hyperfine interaction, particularly when the parent material is $\left(\mathrm{CH}_{3}\right)_{3} \mathrm{SnCl}$ indicates that mechanism (2) is more realistic, but no definite assignment is proposed at this time. This view is further borne out by observations with the last group.

The results for $\mathrm{CH}_{3} \mathrm{SiCl}_{3}$, the only example in the third category, are consistent with proton abstraction by the methyl radicals on neutral $\mathrm{CH}_{3} \mathrm{SiCl}_{3}$ to produce $\mathrm{CH}_{2} \mathrm{SiCl}_{3}$. This process is similar to that described by Kerr, Slater, and Young in the gas phase [2a]. The time-intensity curves indicated that additional recombination process may also obe present. For comparative purposes, we wish to point out some of the differences noted by Roncin $[2 \mathrm{~b}]$ in his investigations with $\gamma$-irradiation. With trimethylchlorosilane, the $\mathrm{CH}_{2}\left(\mathrm{CH}_{3}\right)_{2} \mathrm{SiCl}$ radical is somewhat similar to the radical $\mathrm{CH}_{2} \mathrm{SiHCl}_{2}$ radical discussed earlier in this paper and believed to be formed by a slower secondary reaction. In methyltrichlorosilane Roncin observed $\cdot \mathrm{CH}_{2} \mathrm{SiCl}_{3}$ and $\cdot \mathrm{SiCl}_{3}$ in a ratio of 2.5 to 1 and in tetramethylsilane the radical $\mathrm{CH}_{2} \mathrm{Si}\left(\mathrm{CH}_{3}\right)_{3}$ is found. This points out the greater importance of initial $\mathrm{C}-\mathrm{H}$ and $\mathrm{Si}-\mathrm{Cl}$ bond cleavage at the higher energies.

The importance of these trends is amplified by some preliminary studies on cocondensed 1:1 mixtures. As noted previously, $\mathrm{CH}_{3} \mathrm{SiCl}_{3}$ produces a strong methyl signal and somewhat weaker triplet spectrum immediately upon irradiation. No spectrum is observed when $\mathrm{HSiCl}_{3}$ is irradiated under comparable conditions. However, when the two materials are cocondensed and irradiated neither the methyl nor the triplet spectrum is observed. Rather, an anisotropic spectrum somewhat similar to that obtained in $\mathrm{CH}_{3} \mathrm{GeCl}_{3}$ after nine days is observed.

Similarly for $\mathrm{CH}_{3} \mathrm{GeCl}_{3}+\mathrm{HSiCl}_{3}$ a nonadditive spectrum occurs, and again as with the two previous cases noted in the table very considerable depletion or absence of $\mathrm{CH}_{3} \cdot$ is obtained. Presently it is consistent to presume intermolecular processes occur, initiated by $\mathrm{M}-\mathrm{CH}_{3}$ cleavage:

$$
\begin{aligned}
& \mathrm{CH}_{3} \mathrm{MCl}_{3} \longrightarrow \mathrm{CH}_{3} \cdot+\cdot \mathrm{MCl}_{3} \quad(\mathrm{M}=\mathrm{Si}, \mathrm{Ge}) \text {, and } \\
& \mathrm{CH}_{3} \cdot+\mathrm{HSiCl}_{3} \longrightarrow \mathrm{CH}_{4}+\cdot \mathrm{SiCl}_{3} .
\end{aligned}
$$

Future efforts will thus be directed to evaluating possible $\mathrm{CH}_{4}$ production by the mass spectrometric method described in this paper.

\section{Conclusions}

The irradiation of organometallic compounds has demonstrated that only low energy irradiation is required to break the $\mathrm{M}-\mathrm{C}$ bond. By following the spectral changes as a function of time it has been demonstrated that primary and secondary processes can both be important at liquid nitrogen temperature. Furthermore, the importance of low temperature reactions in order to produce new or novel compounds or radicals has been suggested by the studies of cocondensed mixtures.

\section{References}

[1] Friswell, N. J., and Gowenlock, B. G., Advances in Free Radical Chemistry, Vol. 1, p. 39, G. H. Williams, ed. (Academic Press, N.Y., 1965).

[2a] Kerr, J. A., Slater, D. H., and Young, J. C., J. Chem. Soc. (A) 1966104.

[2b] Roncin, J., Mol. Cryst. 3, 117 (1967).

[3] Morton, J. R., Chem. Rev. 64, 453 (1964).

[4] Symons, M. C. R., and Atkins, P. W., Inorganic Free Radicals (American Elsevier Press, N.Y. 1967).

[5] Kokoszka, G. F., and Brinckman, F. E., Chem. Comm. 1968, 349.

[6] Fessenden, R. W., and Schuler, R. H., J. Chem. Phys. 45, 1845 (1966).

[7] Leray, N., and Roncin, J., J. Chem. Phys. 42, 800 (1965).

[8] Ten percent valley definition. See J. H. Beynon, Mass Spectrometry and Its Applications to Organic Chemistry, p. 51-54 (Elsevier Publ. Co., Amsterdam, 1960).

[9] Shrader, D. M., J. Chem. Phys. 46, 3895 (1967) and references cited therein.

[10] Nay, M. A., Woodall, G. N. C., Strausz, O. P., and Gunning, H. E., I. Amer. Chem. Soc. 87, 179 (1965).

[11] See for example, Tench, A. J., J. Chem. Phys. 38, 593 (1963) and references cited therein.

(Paper 73A2-545) 